\title{
Numerical simulation of concrete pile groups' response bored in cemented sand deposit under axial static load testing
}

\author{
Mehdi Aghayarzadeh* and Hadi Khabbaz \\ University of Technology Sydney, School of Civil and Environmental Engineering, 2007 Sydney, Australia
}

\begin{abstract}
For a safe foundation to perform as desired, the ultimate strength of each pile must fulfil both structural and geotechnical requirements. Pile load testing is considered as a direct method of determining the ultimate bearing capacity of a pile. Pile groups are commonly used in foundation engineering and due to the difficulties and cost of full-scale load tests, most pile group tests are scaled down regardless of whether performed in the field or laboratory. In this paper, it is aimed to simulate the behaviour of concrete bored pile groups under axial static load testing using PLAXIS 3D software and to compare the obtained results with measured curves in an experimental study introduced in the literature. In numerical simulation, to account for the stiffness variation existing inside the pile group and to achieve a reasonable correlation between measured and predicted load-settlement curves three different analyses, including linear elastic, completely non-linear, and a combination of non-linear and linear analyses were performed. The results indicate that the combined non-linear and linear analysis seems a suitable analysis for pile group behaviour prediction.
\end{abstract}

\section{Introduction}

The behaviour of single piles under axial loading was examined in detail by many investigators [1-3]. However, the behaviour of pile groups is more complex and has not adequately been examined or understood $[4,5]$. In spite of some theoretical advances in the analyses and prediction of pile group behaviour in the last few decades, analyses are still based largely on simplifications of the problem or the constitutive behaviour of the soil. Hence, static load tests on group of piles remain the most reliable means of assessing the pile group response under design loads [5]. Some laboratory and field pile group tests under vertical loads have already been performed and published $[6,7]$. However, due to the difficulties and the cost of full-scale load tests, most pile group tests were scaled down, regardless of whether they were carried out in the field or laboratory. Hence, there is an objective need for prediction of the pile group response under static load testing using proper numerical modelling.

Aghayarzadeh et al. [8] evaluated the interaction of reaction piles on the concrete bored test pile during the static load testing using three-dimensional finite element program applying an advanced soil model (i.e. hardening soil model). In this study, a number of different factors affecting the load-displacement curve of test pile such as the length, the diameter, the number, and the type (e.g. steel pipe pile or solid concrete pile) of reaction piles were evaluated. The obtained results were compared with the recommendations of ASTM D1143 [9] to introduce the minimum distance in which the effect of interaction between test pile and the reaction piles is minimised. Comodromos et al. [10] conducted a numerical analysis using FLAC 3D software applying Mohr-Coulomb soil model to evaluate the influence of the interaction between the test pile and the reaction piles on the stiffness of the single piles and pile groups. In the latter study, different layouts of pile groups numerically analysed to establish load-settlement relationships. It was concluded that the interaction could significantly affect the stiffness efficiency factors of the groups. The efficiency factor for a $3 \times 3$ group with spacing of $3 \mathrm{D}$, where $\mathrm{D}$ is the pile diameter of the pile, was in the order of 0.3 and increased for larger pile spacing.

In this study, the behaviour of two real case concrete bored piles groups in cemented sand deposit represented by Ismael [4] are evaluated by PLAXIS 3D finite element software. During the numerical simulation a combined nonlinear and linear analysis is performed to capture a reasonable correlation with field measurements.

\section{Case study overview}

\subsection{Site and soil characteristics}

As explained by Ismael [4], a test site, located in South Surra, Kuwait was selected on flat and cemented sands existing from the ground surface to an extended depth. These cemented sands are coastal plain deposits, which are a heterogeneous mixture of gravel, sand, silt, clay, and

* Corresponding author: mehdi.aghayarzadeh@student.uts.edu.au 
authigenic minerals. One auger boring was drilled at the test site to a depth of $6.5 \mathrm{~m}$. The soil profile consists of medium dense weakly cemented silty sand layer to a depth of $4.5 \mathrm{~m}$. This is underlain by very dense silty sand with cemented lumps to the bottom of the borehole. Groundwater was not encountered within the depth of the boreholes. Figure 1 indicates a summary of the soil condition. Detailed information on soil properties, including moisture contents, bulk unit weights, SPT-N values, dynamic CPT results, and pressuremeter modulus can be found in Ismael's study [4].

\subsection{Pile groups characteristics}

As mentioned by Ismael [4], two test pile groups, each consisting of five piles and capped with a rigid cap resting on the ground, installed in site and were tested in compression. The piles were spaced at three-pile diameters in "group A" and at two-pile diameters in "group B". The piles in both groups were $0.1 \mathrm{~m}$ in diameter and $2.25 \mathrm{~m}$ deep. All static load tests were carried out by a reaction beam method in which the reaction piles were installed far enough respect to the test pile, minimising the interaction effect of test and the reaction piles. Groups A and B were installed $4 \mathrm{~m}$ apart from each other. To install the pile groups, the piles were augered to a depth of $2.25 \mathrm{~m}$ and protruded $0.1 \mathrm{~m}$ above the ground level. Then, a $0.4-\mathrm{m}$-thick rigid reinforced concrete cap was subsequently poured on the pile groups. Details of the pile spacing in the groups and dimensions of the pile caps are shown in Figures $2 \mathrm{a}$ and $2 \mathrm{~b}$.

\section{Numerical model characteristics}

The numerical simulations of the pile groups were performed using the finite element PLAXIS 3D software version 2017. The soil and pile clusters were modelled using 10-noded tetrahedral elements and a very fine mesh was considered in the three-dimensional model to capture a better gradient along the pile. At the bottom level of the model, all movements were restrained, whereas, at the lateral external sides, lateral movements perpendicular to the boundary were prohibited. Lateral sides of the computational domain were taken sufficiently away from the pile group to avoid the boundary effect. The borehole option described in the program was used to define the soil stratigraphy and the ground surface level. Groups A and $\mathrm{B}$ were modelled in two different numerical models with $20 \mathrm{~m} \times 20 \mathrm{~m} \times 6.5 \mathrm{~m}$ dimensions. In numerical simulation, a plate element was used to model the pile cap and a linear elastic non-porous and isotropic material model was assigned to the piles. The material properties of piles and the pile cap used in the model are summarised in Table 1. In addition, interface elements were introduced between the pile and the soil to simulate the interaction of pile-soil system and the interface strength reduction factor $\left(R_{\text {int }}\right)$ was assumed to be equal to 1 . Figure 3 shows the finite element scheme of the modelled pile group.

In reality, it is well understood that the modulus of a soil mass decreases with increasing the strain level. According to Ju [11] and Gowthaman and Nasvi [12], for a group of piles, it would be expected that the strain level increases in the vicinity of pile shaft; i.e. the stiffness of the soil at this narrow zone close to the pile shaft is smaller than that between the piles at some distance from the pile shaft. Therefore, to account for this stiffness variation, in simulation of pile group behaviours normally three different types of finite element analyses are performed: (i) a linear elastic analysis (LE) where all soils including the soil adjacent to the pile shaft (Zone A in Figure 4) and the soil between the piles (Zone B in Figure 4) are assumed to be linear elastic (ii) a completely nonlinear (CNL) analysis, where both the soil adjacent to the pile shaft and the soil between the piles are modelled using the hardening soil (HS) model (iii) a combined nonlinear and linear analysis (NL-LE) in which the soil close to the pile shaft is modelled using the HS model, while the soil in the remaining area is modelled as linear elastic model.

In the combined analysis, two different sizes in the adjacent to the pile shaft are selected: zone extending to a distance (d) is equal to $\mathrm{D} / 2$ from the pile shaft and zone extending to a distance (d) is equal to $\mathrm{D} / 4$ ( $D$ is the pile diameter). The pile group layout of the combined analysis is shown in Figure 4.

According to Wehnert and Vermeer [13], the stress dependency stiffness of the HS model is described by $E_{\text {oed }}, E_{50}$ and $E_{u r}$, where, $E_{\text {oed }}$ is the oedometer stiffness being defined as a tangent stiffness modulus. Other two stiffness parameters $E_{50}$ and $E_{u r}$ are related to the standard drained triaxial tests. Referring to Scahnz et al. [14], for engineering practice it can be assumed that $E_{u r}=3 E_{50}$ and $E_{\text {oed }}=E_{50}$.

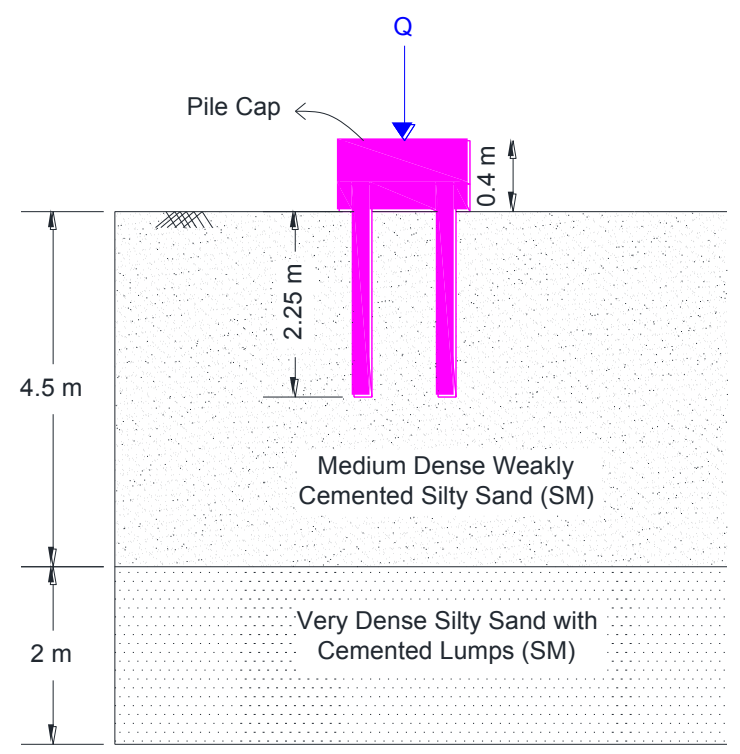

Fig. 1. Summary of soil condition and cap dimensions 


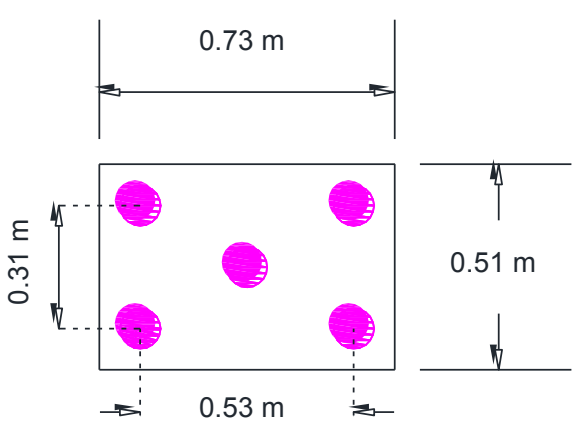

(a)

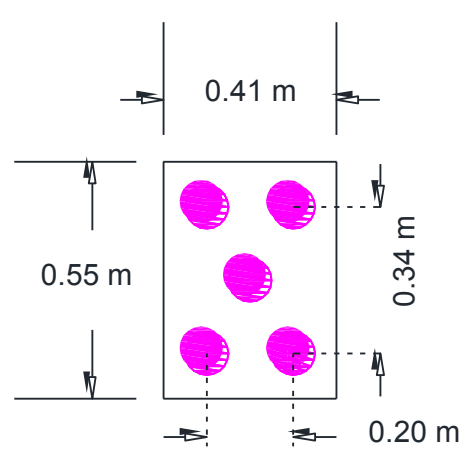

(b)

Fig. 2. (a) plan view of "Group A" (b) plan view of "Group B"

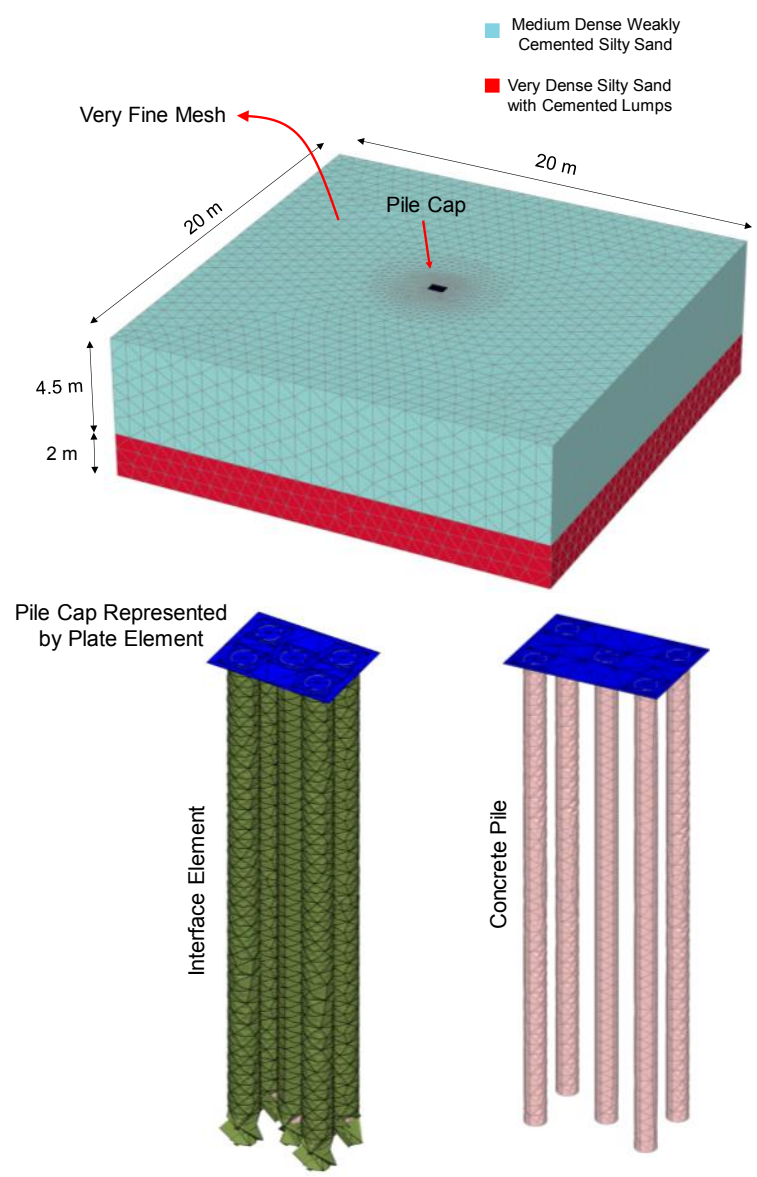

Fig. 3. Finite element model of pile group and adjacent soil
Model parameters used for linear isotropic elastic model used in concrete piles and cap are indicated in Table 1. In addition, the soil properties assigned for hardening soil model were approximated based on correlation of the results of a drained triaxial test obtained for Mohr-Coulomb and hardening soil model using the soil test facility defined in PLAXIS software. The obtained correlation is shown in Figure 5. The soil properties corresponding to each soil model used in numerical simulation are summarised in Table 2.

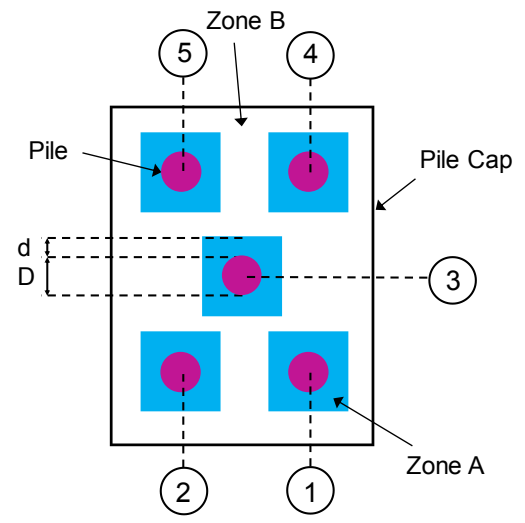

Fig. 4. Pile group layout for different analyses

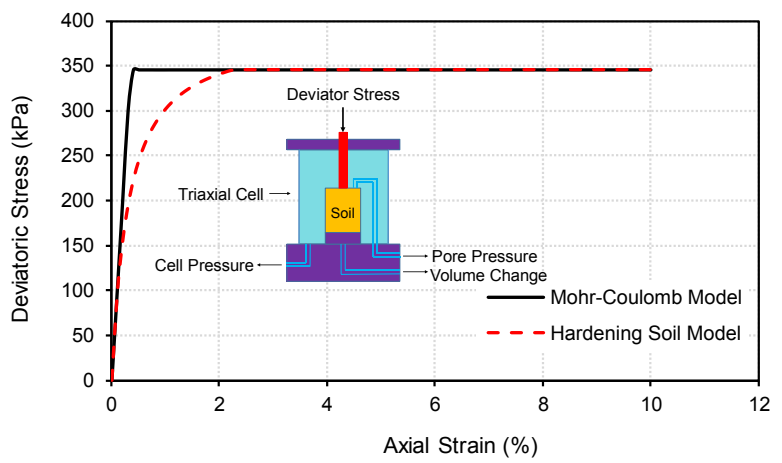

Fig. 5. Correlation of Mohr-Coulomb and hardening soil models in simulated drained triaxial test

\section{Pile group behaviour simulation}

In numerical simulation procedure, MC model was assigned to the soil around the pile group in all analyses, while LE, HS and LE-HS models were assigned to the soil around the pile shaft and between the piles. The loadsettlement curves measured in site for pile groups A and $\mathrm{B}$ are shown in Figures $6 \mathrm{a}$ and $6 \mathrm{~b}$, respectively. In order to predict the load-settlement curve in each pile group, three types of analyses as mentioned earlier (LE, CNL, and NL-LE) were performed.

Table 1. Properties of pile foundation

\begin{tabular}{ccc}
\hline Properties & Pile & Pile Cap \\
\hline$\gamma\left(k N / m^{3}\right)$ & 25 & 25 \\
\hline$E(G P a)$ & 30 & 30 \\
\hline$v$ & 0.2 & 0.2
\end{tabular}


Table 2. Soil parameters used in different models: linear elastic (LE), Mohr-Coulomb (MC) and hardening soil (HS)

\begin{tabular}{ccccc}
\hline Soil Properties & $\begin{array}{c}\text { Medium Dense } \\
\text { Weakly } \\
\text { Cemented Silty } \\
\text { Sand }\end{array}$ & $\begin{array}{c}\text { Very Dense } \\
\text { Silty Sand } \\
\text { with } \\
\text { Cemented } \\
\text { Lumps }\end{array}$ \\
\cline { 2 - 5 } LE & MC & HS & MC \\
\hline$\gamma\left(k N / m^{3}\right)$ & 18.1 & 18.1 & 18.1 & 19.5 \\
\hline$E(M P a)$ & 100 & 100 & - & 120 \\
\hline$v$ & 0.3 & 0.3 & - & 0.3 \\
\hline$c^{\prime}(k P a)$ & - & 20 & 20 & 0 \\
\hline$\varphi^{\prime}($ degree $)$ & - & 35 & 35 & 43 \\
\hline$\psi($ degree $)$ & - & 5 & 5 & 13 \\
\hline$E_{50}^{r e f}(k P a)$ & - & - & 75 & - \\
\hline$E_{o e d}^{r e f}(k P a)$ & - & - & 75 & - \\
\hline$E_{u r}^{r e f}(k P a)$ & - & - & 225 & - \\
\hline$p^{r e f}(k P a)$ & - & - & 100 & - \\
\hline$v_{u r}$ & - & - & 0.2 & - \\
\hline$R_{f}$ & - & - & 0.9 & - \\
\hline$m$ & - & - & 0.7 & - \\
\hline
\end{tabular}

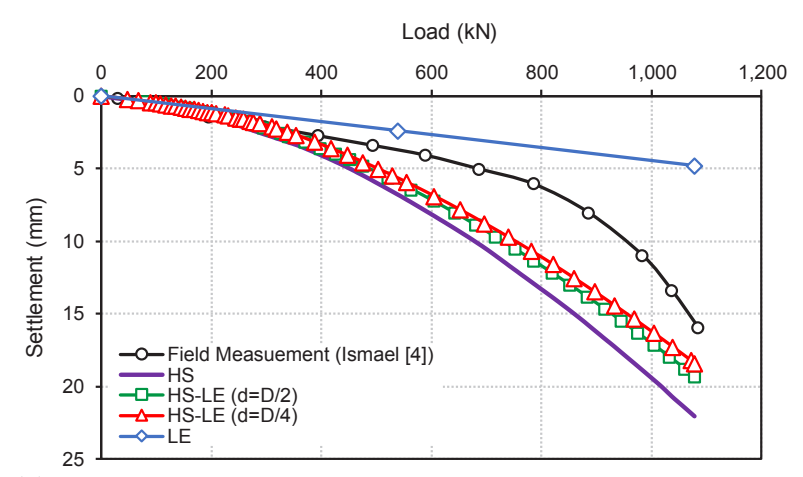

(a)

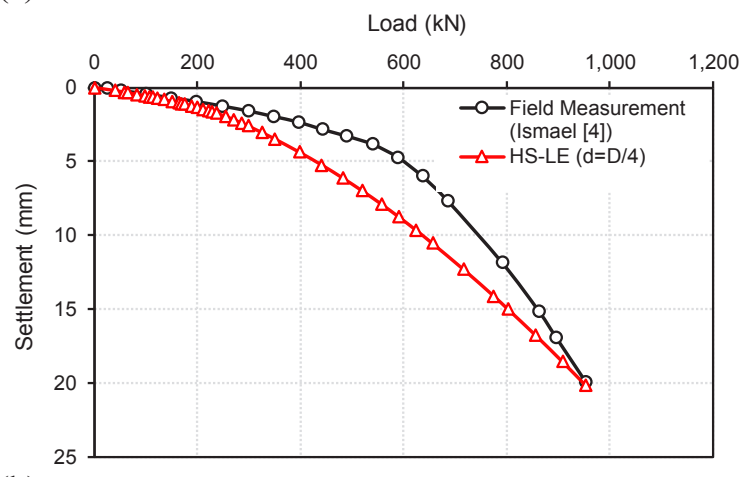

(b)

Fig. 6. (a) measured and predicted load-settlement curves for "Group A" and (b) measured and predicted load-settlement curves for "Group B"

Referring to Figure $6 \mathrm{a}$, the completely non-linear (CNL) analysis (HS model) of pile group A causes an over-prediction of group settlement (or under-estimation of soil stiffness); thus, in the maximum applied load (1078 $\mathrm{kN})$ the numerical analysis indicates a group settlement of $22 \mathrm{~mm}$, which is $38 \%$ higher than the measured settlement in site. At the same time, the linear elastic (LE) analysis
(LE model) under-predicts the group settlement drastically, since this model ignores the soil nonlinearity and influences from the group response. Hence, this analysis is not suitable when soil nonlinearity affects the interaction. Although HS model is known as a model that can capture the actual nonlinear behaviour of soil compared to MC and LE models, accounting for the stiffness variation that exists inside the pile group a combined analysis (NL-LE) seems necessary to be employed. As mentioned above, in the narrow zone close to the pile shaft stiffness of the soil is smaller than that in the space between the piles away from the pile shaft. Therefore, HS model is assigned to Zone A with two different distances from the pile shaft $(\mathrm{d}=\mathrm{D} / 2$ and $\mathrm{d}=\mathrm{D} / 4)$, while the remaining soil inside the group area is assigned the LE model. As shown in Figure 6a, the combined analysis (HS-LE models) indicates more precise prediction when the thickness of Zone $\mathrm{A}$ is assumed to be equal to a half of pile diameter $(\mathrm{d}=\mathrm{D} / 2)$. In this case, the predicted load-settlement curve shows a better correlation with the measured curve, so in this case the maximum predicted settlement decreased approximately by $18 \%$ compared to the recorded settlement during completely nonlinear analysis. In the next stage, the thickness of Zone A decreased to D/4 and a slight improvement (around 5\%) was observed in the load-settlement curve compared to the previous stage $(d=D / 2)$. The obtained results prove that by assigning HS model to Zone $A(d=D / 2)$ while the remaining area (Zone B) is assigned LE model, it is possible the mechanism of the pile group can be captured properly. However, because by decreasing the Zone A dimensions to $\mathrm{D} / 4$ from the pile shaft a better correlation was observed between the measured and the predicted load-settlement curves; hence, this distance was considered as a suitable distance for analysis. Considering this distance, the behaviour of pile group B was evaluated under working load up to $954 \mathrm{kN}$. From Figure 6b, it is crystal clear that the predicted load settlement, considering Zone A to the distance D/4, shows a reasonable correlation with measured load-settlement curve. so both curves indicate a settlement of $20 \mathrm{~mm}$ at the maximum applied force.

Figure 7 compares the load-settlement curve for the single pile and the average load-settlement curves for the pile group B. As demonstrated in Figure 7, a reasonable correlation between the measured and the predicted averaged load-settlement can be observed. For plotting the average load-settlement curve in the numerical model, the settlement of the individual pile in the group was not measured separately because the pile cap was considered rigid enough so that all piles can be assumed to have almost the same settlement. Based on this assumption, the recorded force over each single pile head (due to the working load applied over the group cap) can be averaged and drawn respect to the recorded settlement of the pile group in each load increment (190, 381, 572, 763, 954 $\mathrm{kN}$ ). Figure 7 reveals that both the average measured and predicted curves show a greater settlement than the settlement of single piles under lower loads (initial elastic range), while at larger loads, the settlement of the single pile exceeds since it approaches failure at smaller loads. 


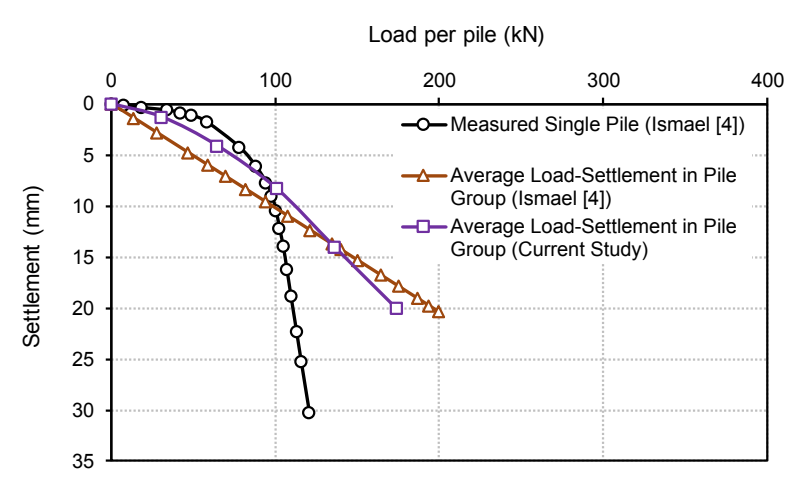

Fig. 7. Predicted and measured average load-settlement of pile group B versus the single pile

\section{Further assessment of pile group behaviour}

Since prediction of pile group B behaviour showed reasonable correlation with the measured data in site, hence in this section the behaviour of group B under axial static load testing is further analysed.

The design of pile groups in sand is usually controlled by settlement considerations; therefore, the group settlement ratio $\left(R_{S}\right)$ will be a very important factor in determining the settlement of the pile groups at the working loads if the settlement of single piles is known [4,5]. According to Poulos and Davis [15], the group settlement ratio $\left(R_{S}\right)$ is defined as the ratio of the settlement of a pile group $\left(S_{g}\right)$ to that of single pile $(S)$ at the same average load per pile. Figure 8 indicates this ratio versus various group settlement levels. It can be seen that at the beginning, the predicted group settlement ratio increases to 3.4 and then decreases continuously when settlement increases and reaches to less than 0.5. The discrepancy observed at the beginning of curve (Figure 8) is attributed to the accuracy of read data from the measured curves. The overall trend observed in Figure 8 seems reasonable because, as explained in Figure 7, at relatively small loads a single pile experiences lower settlement than the average group settlement; however, in higher loads this trend is reversed.

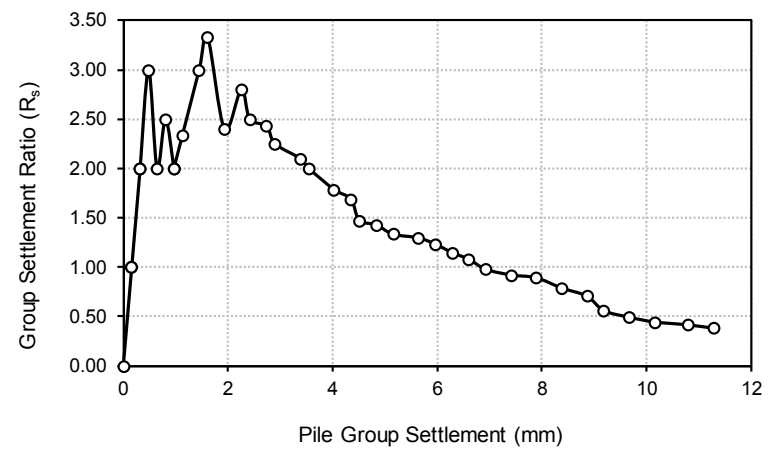

Fig. 8. Group settlement ratio versus pile group settlement

The pile group layout is displayed in Figure 4 in which each pile has specified number. Pile No.3 represents the central pile in group B. The variations of top load $\left(T_{i}\right)$ and base load $\left(B_{i}\right)$ ( $i$ indicates the pile number) of this pile due to working load applied over the group cap in five different load increments $(190,381,572,763$, and 954 $\mathrm{kN}$ ) are shown in Figure 9. As can be seen in Figure 9, the corner piles (NO. 1, 2, 4 and 5) have larger loads (the pile head and base loads) compared to the central pile (NO. 3). This finding is in a good agreement with Dai et al. [5] study results. This result confirms the elasticity concept that if a pile cap is considered flexible, hence the loads on every pile are the same, and it is expected that the centre pile to undergo the largest settlement, proving it has the lowest stiffness. However, since the same settlement is considered for all piles; therefore, it is expected that the centre pile to carry the smallest load as indicated in Figure 9. For instance, the pile head force predicted in pile NO. 4 (one of the corner piles) is $18 \%$ higher than the central pile, while for the base load, this difference increases to $26 \%$. Figure 10 illustrates the ratio of the individual pile head load to the average individual head load in the group $\left(Q_{i} / Q_{\text {ave }}\right)$ versus the average individual head load $\left(Q_{\text {ave }}\right)$. It is clear that this ratio for piles NO. 2 and 4 fluctuates between 1 and 1.2, while for piles NO. 1 and 5 are changing around 1. For the central pile (NO. 3) this ratio is less than 1 (around 0.9), which confirms the lower stiffness and lower load portion of this pile compared with the corner piles. Figure 11 depicts each individual pile settlements versus applied loads. Referring to the Figure 11 , it can be inferred that at the same load, pile NO. 3 indicates the largest settlement. On the other hand, at the same settlement, corner piles mobilise higher resistance. For example, based on the $Q_{10 \%}$ approach (load corresponding to the displacement equal to the $10 \%$ of pile diameter) the bearing capacity of pile NO. $4(117 \mathrm{kN})$ is estimated to be $17 \%$ higher than the capacity of pile NO. $3(100 \mathrm{kN})$.

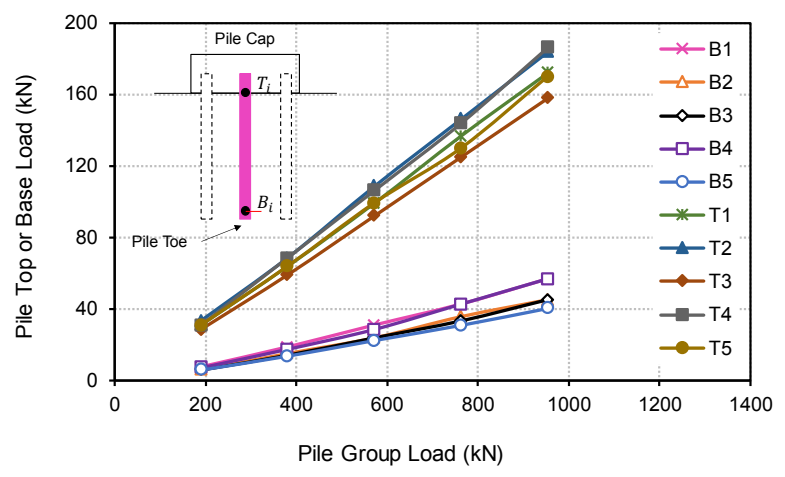

Fig. 9. Top $\left(T_{i}\right)$ and base $\left(B_{i}\right)$ load in central pile in pile group B 


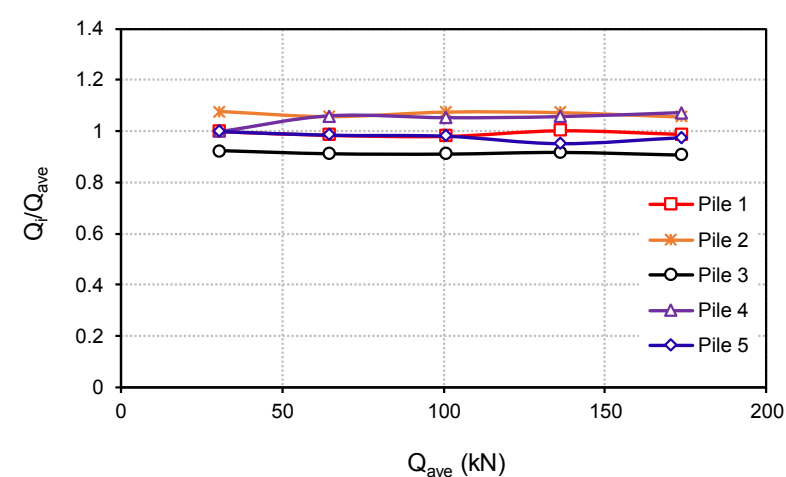

Fig. 10. Ratio of the individual pile load to the averaged individual load

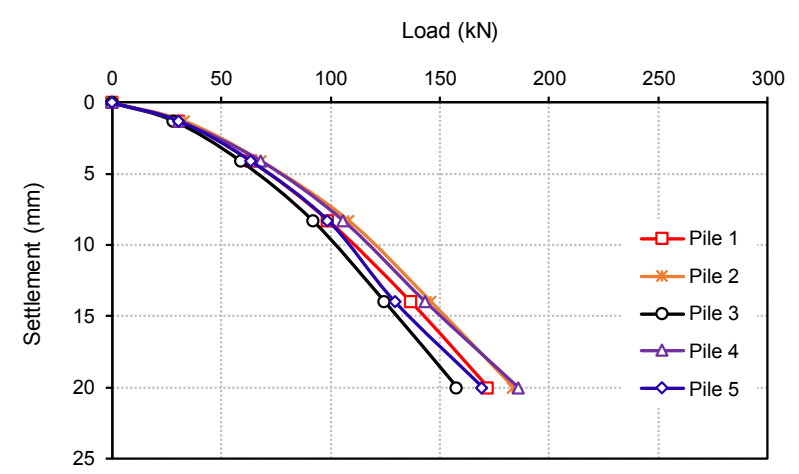

Fig. 11. Individual pile load-settlement curve for pile group B

\section{Conclusions}

In this study, the axial behaviour of concrete bored piles under static load testing, using the three-dimensional numerical simulation was examined. From the findings of this study it can be concluded that a combined analysis of linear and nonlinear (LE-NL) i.e. a nonlinear interface zone of soil close to the pile shaft and a linear elastic soil beyond this zone, can obtain a much better prediction of the group pile settlement compared to a completely nonlinear analysis. In addition, during the numerical simulation it was proved that due to lower stiffness of the central pile, this pile can support a lower load portion compared to corner piles. Using the conventional definition of the ultimate load capacity, defined as the load causing a settlement of $10 \%$ of the pile diameter, the bearing capacity of one of the corner piles (pile NO. 4) estimated $17 \%$ higher than the central pile (pile NO. 3 ).

\section{References}

1. G.G. Meyerhof, Bearing Capacity and Settlement of Pile Foundations, J. Geotech. Engrg. Div., ASCE, 102(3), 195-228 (1976).

2. A.S. Vesic, Design of Pile Foundations, Nat. Cooperative Hwy. Res. Program Synthetic of Pract, No. 42, Transportation Research Board, Washington, D.C. (1977).
3. B.M. Das, Fundamentals of Geotechnical Engineering, Principles of foundation engineering, $4^{\text {th }}$ Ed., Brooks/Cole Publishing Co, Pacific Grove, Calif (1999).

4. N.F. Ismael, Axial Load Tests on Bored Piles and Pile Groups in Cemented Sands, J. Geotech and Geoenvironmental Eng., ASCE, 127(9), 766-773 (2001).

5. G. Dai, R. Salgado, W. Dong, Y. Zhang, Load Tests on Full-Scale Bored Pile Groups, Can. Geotech. J., 49, 1293-1308 (2012).

6. X. Bai, W. He, J. Jia, Y. Han, Experimental Study on the Interaction Mechanism of Cap-Pile Group-Soil, Marine Georesources and Geotechnology Geotech., 24(3), 173-182 (2006).

7. A.G. Yetginer, D.J. White, M.D. Bolton, Field Measurements of the stiffness of Jacked Piles and Pile Groups, Geotechnique J., 56(5), 349-354 (2006).

8. M. Aghayarzadeh, H. Khabbaz, B. Fatahi, Evaluation of Reaction Piles Effect on Test Piles in Static Load Testing Using Three-Dimensional Numerical Analysis, $10^{\text {th }}$ International Conference on Stress Wave Theory and Testing Methods for Deep Foundations, ASTM International, West Conshohocken, PA, 2019.

9. ASTM D1143: Standard Test Methods for Deep Foundations under Static Axial Compressive Load, ASTM International, (2013).

10. E.M. Comodromos, C.T. Anagnostopoulos, M.K. Georgiadis, Numerical Assessment of Axial Pile Group Response Based on Load Test, Computers and Geotechnics., 30, 505-515, (2003).

11. J. Ju, Prediction of the Settlement for the Vertically Loaded Pile Group using 3D Finite Element Analyses, Marine Georesources and Geotechnology, 33, 264-271, (2015).

12. S. Gowthaman, C.M. Nasvi, Three-Dimensional Numerical Simulation and Validation of LoadSettlement Behaviour of a Pile Group under Compressive Loading, Engineer, 1(1), 9-21, (2018).

13. M. Wehnert, PA. Vermeer, Numerical Analyses of Load Tests on Bored Piles, Numerical methods in Geomechanics, 505-511, (2004).

14. T. Schanz, PA. Vermeer, PG. Bonnier, The Hardening Soil Model: Formulation and Verification, International Symposium of Beyond 2000 in Computational Geotechnics, Amsterdam, 281-296, (1999).

15. H.G. Poulos, E.H. Davis, Pile Foundation Analysis and Design. Wiley, New York, (1980). 